\title{
Vagal modulation of resting heart rate in rats: the role of stress, psychosocial factors, and physical exercise
}

\author{
Luca Carnevali and Andrea Sgoifo* \\ Stress Physiology Laboratory, Department of Neuroscience, University of Parma, Parma, Italy
}

\section{Edited by:}

Daniel Boullosa, Universidade

Católica de Brasília, Brazil

\section{Reviewed by:}

Arto J. Hautala, Verve Research,

Finland

Ben N. Greenwood, University of

Colorado Boulder, USA

*Correspondence:

Andrea Sgoifo, Stress Physiology

Laboratory, Department of

Neuroscience, University of Parma,

Parco Area delle Scienze 11/a,

Parma 43124, Italy

e-mail: andrea.sgoifo@unipr.it
In humans, there are large individual differences in the levels of vagal modulation of resting heart rate (HR). High levels are a recognized index of cardiac health, whereas low levels are considered an important risk factor for cardiovascular morbidity and mortality. Several factors are thought to contribute significantly to this inter-individual variability. While regular physical exercise seems to induce an increase in resting vagal tone, chronic life stress, and psychosocial factors such as negative moods and personality traits appear associated with vagal withdrawal. Preclinical research has been attempting to clarify such relationships and to provide insights into the neurobiological mechanisms underlying vagal tone impairment/enhancement. This paper focuses on rat studies that have explored the effects of stress, psychosocial factors and physical exercise on vagal modulation of resting HR. Results are discussed with regard to: (i) individual differences in resting vagal tone, cardiac stress reactivity and arrhythmia vulnerability; (ii) elucidation of the neurobiological determinants of resting vagal tone.

Keywords: autonomic nervous system, heart rate variability, arrhythmias, stress, anxiety, depression, exercise, rat

\section{INTRODUCTION}

The sinoatrial node has an intrinsic rate of spontaneous automaticity that sets the basic rhythm of the heartbeat (Jose and Collison, 1970). The dynamic balance between the sympathetic and parasympathetic (vagal) influences on sinoatrial node activity primarily determines the actual heart rate (HR) of a given physiological state. In healthy individuals, vagal modulation (or "tone") prevails under resting conditions. The role of resting vagal tone in healthy cardiac function has been increasingly recognized over the past 20 years (Levy and Schwartz, 1994). This was predominantly due to the rise of research that applied heart rate variability (HRV) analysis as a window into cardiac autonomic control. Mounting evidence indicates that those individuals showing higher vagal tone than average at rest tend to be more resilient to stress, adapting well across a number of different situations (ElSheikh et al., 2001; Kok and Fredrickson, 2010; Smeets et al., 2010; Souza et al., 2013). On this regard, the beneficial effects of regular physical exercise on cardiac health appear to be mediated by an increase in resting vagal outflow (Smith et al., 1989; Rosenwinkel et al., 2001; Rennie et al., 2003; Soares-Miranda et al., 2009; Fu and Levine, 2013). On the contrary, low levels of vagal modulation may not adequately counteract sympathetic stimulation, leaving the heart vulnerable to ventricular tachyarrhythmias and sudden cardiac death (Schwartz et al., 1988; Esler, 1992; Volders, 2010). Several factors, including chronic life stress, negative personality traits, anxiety and mood states have been associated with

Abbreviations: DMH, dorsomedial hypothalamus; HA, high-aggressive; HAB, high-anxiety behavior; HF, high frequency; HR, heart rate; HRV, heart rate variability; LAB, low-anxiety behavior; LF, low frequency; NA, non-aggressive; NAmb, nucleus ambiguus; NTS, nucleus tractus solitarii; RMSSD, root mean square of successive R-R interval differences; RSA, respiratory sinus arrhythmia; VLF, very low frequency; 5-HT, serotonin. vagal withdrawal and sympathetic predominance (Sloan et al., 1994; Friedman and Thayer, 1998; Rozanski et al., 1999; Gorman and Sloan, 2000; Lucini et al., 2005). Moreover, depression of vagal modulation characterizes cardiovascular pathology (e.g., heart failure) (Sabbah et al., 2011) and strongly predicts cardiac mortality after myocardial infarction (La Rovere et al., 1998). Interventional therapies for restoring the autonomic balance in such psychological and cardiac conditions include pharmacological, biobehavioral, and exercise strategies (Bryniarski et al., 1997; Iellamo et al., 2000; Tsai et al., 2006; Blumenthal et al., 2007; Nolan et al., 2008). Traditionally, pharmacological approaches have mainly been directed at reducing cardiac sympathetic outflow, while overlooking the possibility of enhancing vagal tone. This was presumably due to a lack of a comprehensive understanding of the central neurobiological determinants of resting vagal tone. Preclinical research is now attempting to fill this knowledge gap.

This paper focuses on current and past HRV research in rats that can potentially increase our understanding of the neurobiological mechanisms underlying vagal tone impairment/enhancement. It describes (i) how resting vagal tone is regulated and measured, (ii) the relations among individual differences in resting vagal tone, cardiac stress reactivity, and arrhythmia vulnerability, and (iii) the role of stress, psychosocial factors and physical exercise on the neural determination of resting vagal tone.

\section{ORIGIN, COMPONENTS, AND MEASUREMENTS OF RESTING VAGAL TONE}

Cardiac vagal activity is generated by cardiac vagal pre-ganglionic neurones mainly located in the nucleus ambiguous (NAmb) of the lower brainstem (Figure 1). Their axons innervate 


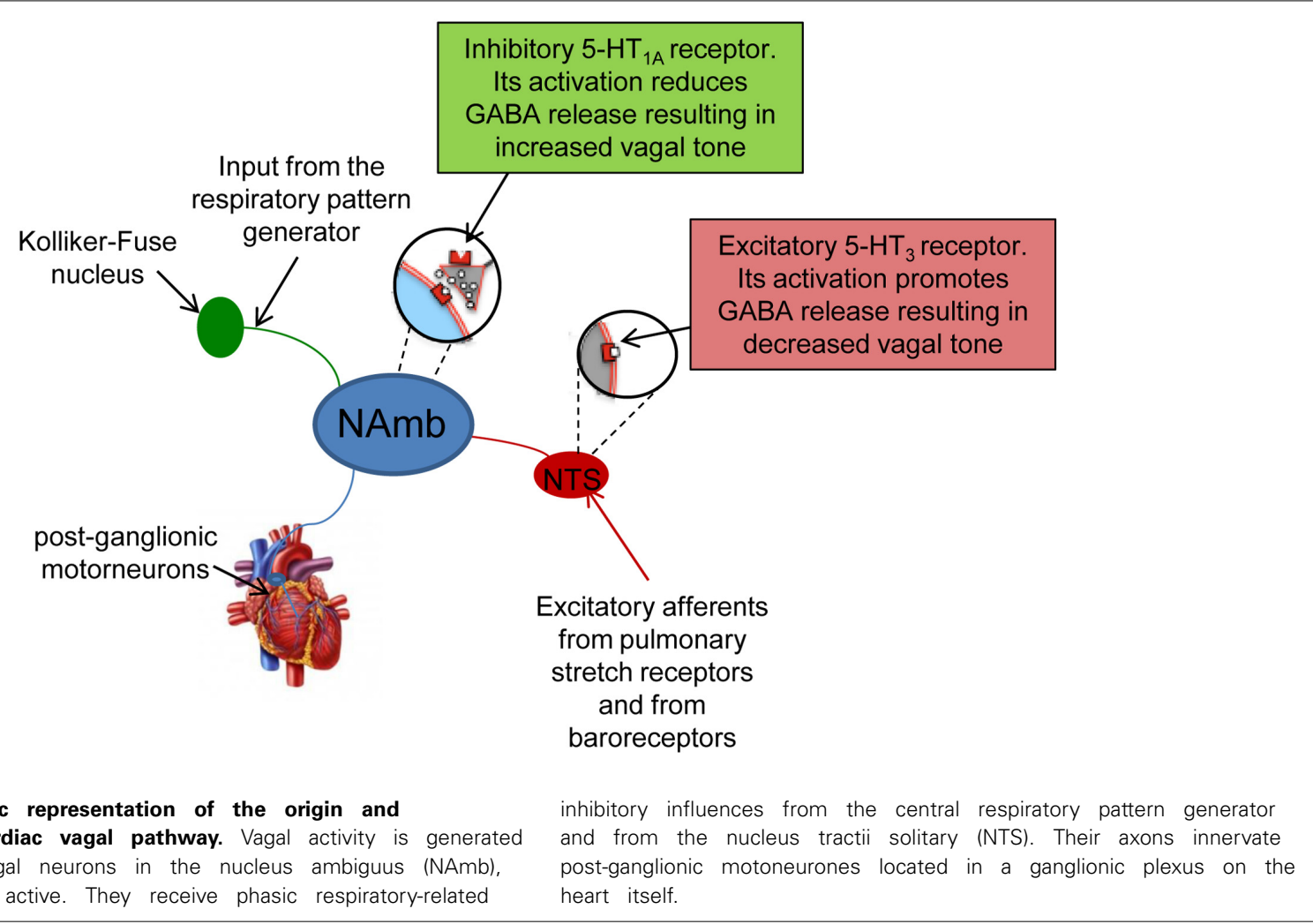

post-ganglionic motoneurones located in a ganglionic plexus on the heart itself (Cheng et al., 1999; Cheng and Powley, 2000) (Figure 1). Under resting conditions, this vagal pathway fires a rapid and continuous signal (or "tonus") to the sinoatrial node, slowing HR via acetylcholine release from efferent vagal nerve discharge. Vagally-released acetylcholine counteracts sympathetic effects both post-synaptically (via cAMP) and pre-synaptically (by reducing noradrenaline release from the sympathetic terminals) (Levy, 1971).

Cardiac vagal activity is dependent on excitatory and inhibitory synaptic inputs (Mendelowitz, 1996), including baroreflex [mediated by the nucleus tractus solitarii (NTS)] and respiratory input (Rentero et al., 2002) (Figure 1). Breathing modulates cardiac vagal activity through two mechanisms: (i) directly by projections from the central respiratory pattern generator, and (ii) indirectly by ascending afferents from lung stretch receptors that are activated during inspiration (Figure 1). These ascending afferents activate GABA-ergic neurons in the NTS that inhibit cardiac vagal motorneurons in the NAmb (Figure 1). Collectively, these mechanisms produce respiratory sinus arrhythmia (RSA)—rhythmic oscillations of HR around its mean value-with increases in HR during inspiration as vagal influence is momentarily suppressed, and decreases in HR during the early expiration phase as vagal influence resumes. Although moment-to-moment HR fluctuations can also be generated in response to, for example, physical movement and blood pressure and thermoregulatory changes, respiration is reliably periodic. Therefore, the strength of vagal influence can be estimated by measuring the rhythmic oscillation in the intervals between consecutive heart beats that are due to RSA-this is called HRV (Task Force, 1996).

HRV analysis is an established tool to estimate cardiac autonomic regulation in humans and animal models. Although the suitability of using HRV parameters to estimate sympathetic modulation is highly debated (Reyes Del Paso et al., 2013), this approach produces reliable measures of vagal tone (Berntson et al., 1997; Reyes Del Paso et al., 2013). Traditional HRV methods fall under the broader description of being either "time-domain" or "frequency domain" analyses. Among time domain measures of HRV, which are assessed with calculations based on statistical operations on R-R intervals (Kleiger et al., 1992), the root mean square of successive R-R interval differences (RMSSD) detects high frequency oscillations of $\mathrm{HR}$, and therefore estimates parasympathetic nervous system activity (Stein et al., 1994). Frequency domain measures are based on spectral analysis of a sequence of R-R intervals and provide information on how power (variance) is distributed as a function of frequency. Usually, three oscillatory components are distinguished in the spectral profile: the very low (VLF), the low (LF), and the high (HF) frequency band. The power of HF band includes respiration-linked oscillations of HR and therefore reflects the modulation of vagus nerve discharge caused by respiration (Berntson et al., 1997), whereas the LF and VLF bands are related to a more gradual interplay between sympathetic and parasympathetic influences (Reyes Del Paso et al., 2013). The power of LF and HF bands is often reported in normalized (relative or fractional) units, which correspond to the relative value of each power in proportion to the total power (usually minus the VLF component). In particular, LF to HF 
ratio is taken as a synthetic measure of sympatho-vagal balance as it estimates the fractional distribution of power (Task Force, 1996).

It is worth mentioning for completeness sake that algorithms based on the chaos theory and nonlinear dynamics have been developed in order to evaluate in greater detail the intrinsic complexity of HRV (for an historical overview of the evolution of the concept of HRV and its application see Billman, 2011). Nonlinear methods are based on the assumption that the mechanisms involved in HR regulation interact with each other in a nonlinear way. The basic concept of nonlinear HRV methods is to try to capture the non-periodic behavior and complexity that exist inside the R-R interval dynamics. Various nonlinear methods have been tested in several sets of R-R interval data (Bigger et al., 1996; Lombardi et al., 1996; Makikallio et al., 1997, 1999; Huikuri et al., 1998, 2000), providing additional prognostic information and complementing traditional time- and frequency-domain analyses.

\section{INDIVIDUAL DIFFERENCES IN RESTING VAGAL TONE: PHYSIOLOGICAL SIGNIFICANCE}

Porges' polyvagal theory (Porges, 1995b) introduces a new perspective relating vagal tone during steady states (i.e., resting vagal tone) and vagal reactivity in response to environmental demands. According to this theory, measures of resting vagal tone are informative of an organism's ability to maintain homeostasis and the potential responsiveness of that organism. In particular, high levels of resting vagal tone can be considered a sign of autonomic flexibility, the capability of the parasympathetic nervous system to generate adequate responses to environmental challenges by modifying HR, respiration and arousal (Porges, 1995a,b, 2007; Beauchaine, 2001). On the contrary, depression of vagal modulation may predict mismatches between environmental demands and cardiac (re)-activity, thus increasing vulnerability to cardiac arrhythmias and sudden cardiac death (Schwartz et al., 1988; Esler, 1992; Volders, 2010).

A deeper insight into the complex relations among individual differences in resting vagal tone, cardiac stress reactivity and arrhythmia vulnerability might be facilitated by HRV studies in rats. Conventional methods for HRV research in rats rely on conscious state electrocardiogram (ECG) recorded by telemetry (Sgoifo et al., 1996). By applying this approach, we obtained a detailed characterization of autonomic regulation of resting $\mathrm{HR}$ in two strains of rats, Wild-type and Wistar (Figure 2). Results indicate that Wild-type rats were characterized by higher HR than Wistar counterparts both during the dark/active and light/inactive phases of the daily cycle (Figure 2). HRV analysis allowed unveiling the autonomic determinants underlying the differences in resting HR between these two rat strains. As suggested by the vagal indexes RMSSD and HF power, Wildtype rats were clearly characterized by lower levels of vagal modulation compared to Wistar rats (Figure 2). Consequently,
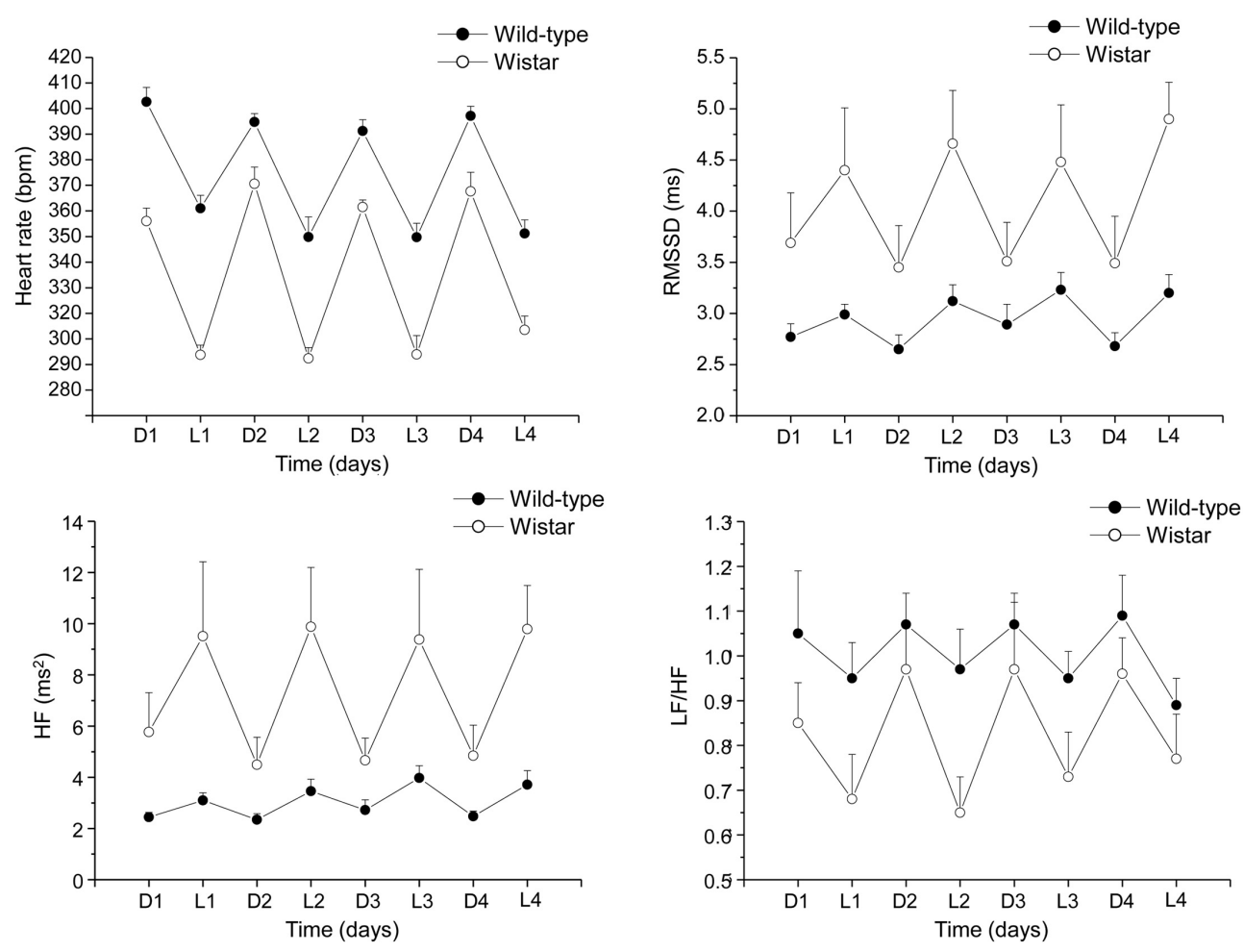

FIGURE 2 | Daily rhythms of heart rate, RMSSD, spectral power in HF band $(0.75-2.5 \mathrm{~Hz})$ and $\mathrm{LF}(0.2-0.75 \mathrm{~Hz})$ to $\mathrm{HF}$ ratio in 4-month-old Wild-type $(n=10)$ and Wistar $(n=10)$ rats. These values (reported as means \pm s.e.m.) were obtained by averaging multiple 2-min segments acquired every hour during

the 12 hours-light and 12 hours-dark phases, as previously described in detail (Carnevali et al., 2013a). Results of Two-Way ANOVA for repeated measures: group difference for heart rate $(F=103.7, p<0.01)$, $\operatorname{RMSSD}(F=6.8$, $p<0.05) \mathrm{HF}(F=7.4, p<0.5)$, and LF to HF ratio $(F=4.4, p<0.05)$ values. 
in Wild-type rats the sympatho-vagal balance (indexed by the LF to HF ratio) was shifted toward a sympathetic dominance (Figure 2). These results indicate that these two rat strains may be viewed as extremes, in terms of cardiac autonomic modulation, within the range of the natural variation of this species, and therefore may represent a valid model for investigating the neurobiological determinants underlying individual differences in resting vagal tone. As discussed before, this inter-individual variability may influence the individual's response to subsequent challenges. Addressing this issue, the two strains were tested under stress conditions (i.e., restraint test). Even though the peak HR reached in response to restraint stress was higher in Wild-type rats, these animals showed reduced overall HR stress responsiveness compared to Wistar rats, as suggested by the values of the area under the response curve above baseline (AUC) (Figure 3). In Wild-type rats, this phenomenon appeared to be related to a reduced vagal flexibility, namely a smaller vagal withdrawal in response to stress, and was coupled with a larger, although modest, vulnerability to arrhythmias compared to Wistar counterparts (Figure 3). Interestingly, a previous study demonstrated that arrhythmia vulnerability was remarkably larger in Wild-Type than Wistar rats in response to a social stressor (Sgoifo et al., 1998). Collectively, these findings support the view that low levels of vagal modulation of resting $\mathrm{HR}$ may be associated with an inability to flexibly generate adequate cardiac responses to stress, even in the absence of evident cardiovascular pathologies.

\section{EFFECTS OF STRESS AND PSYCHOSOCIAL FACTORS ON VAGAL MODULATION OF RESTING HR}

Several humans studies provide clear and convincing evidence that chronic life stress, negative personality traits such us aggressiveness, anger, and hostility, anxiety and mood states contribute significantly to the pathogenesis and progression of cardiac disorders (Sloan et al., 1994; Friedman and Thayer, 1998; Rozanski et al., 1999; Gorman and Sloan, 2000; Lucini et al., 2005; Albus, 2010). Putative underlying mechanisms may include a disruption of the sympatho-vagal balance, through an increase in sympathetic activity and/or a decrease in vagal tone. Rat studies on the integration of stress, psychosocial factors, and cardiac autonomic neural control have just started investigating the underlying mechanistic links.

\section{STRESS}

Several rat studies have investigated the short- and long-term effects of repeated stress exposure on cardiac autonomic regulation. In a study conducted by Trombini et al. (2012), rats
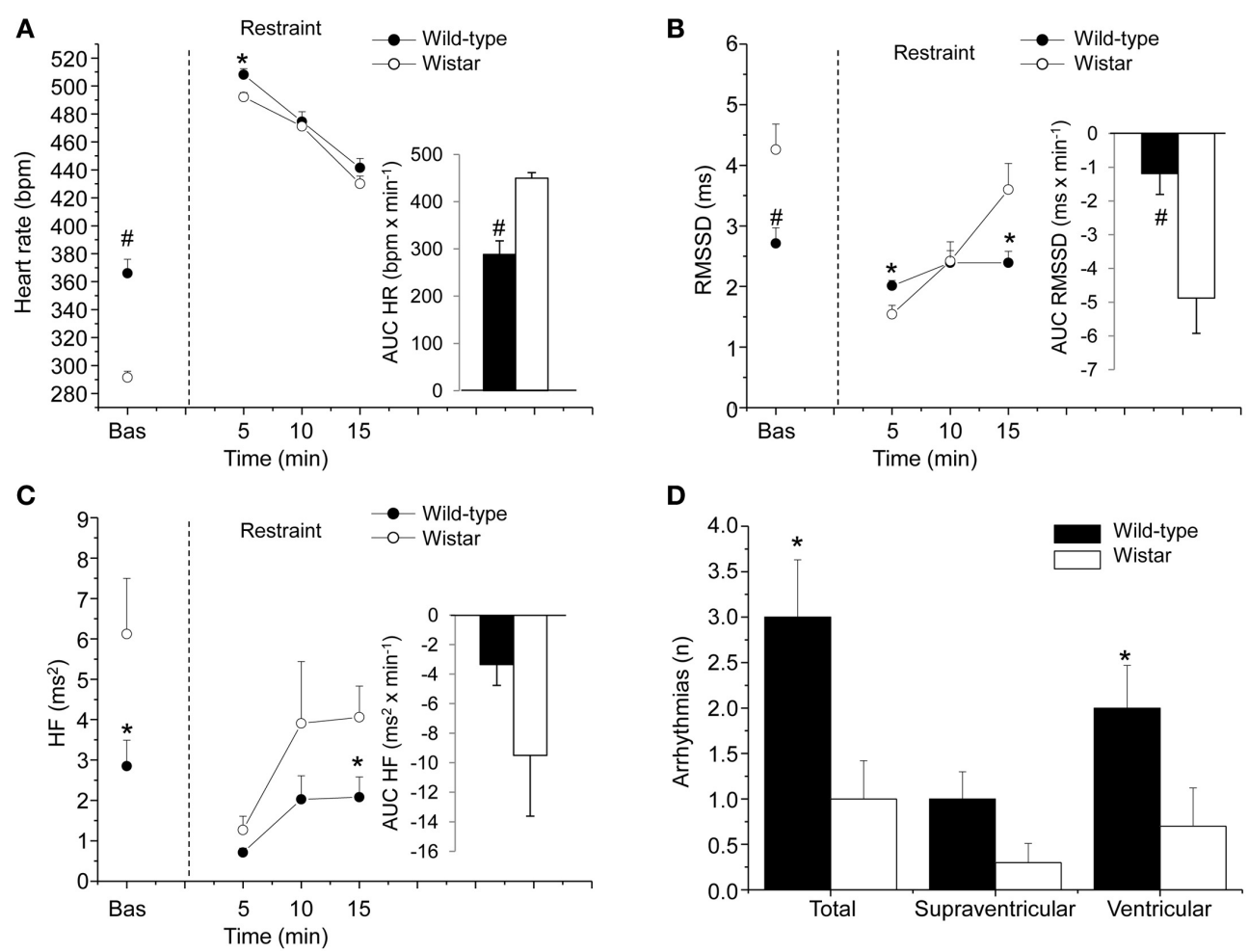

FIGURE 3 | Cardiac response to a restraint stress in 4-month-old Wild-type $(n=10)$ and Wistar $(n=10)$ rats. Panels $(\mathbf{A}-\mathbf{C})$ show the time course of changes in heart rate, RMSSD values, and high-frequency (HF, $0.75-2.5 \mathrm{~Hz}$ ) spectral power, respectively, in baseline conditions (bas, $30 \mathrm{~min}$ ) and during the restraint test $(15 \mathrm{~min})$. Each point during the restraint phase is the mean of 5-min intervals. Inner graphs in (A-C) represent the area under

the response time curve above baseline (AUC) of heart rate, RMSSD, and HF values during the restraint phase. Panel (D) illustrates the incidence of cardiac arrhythmias during the restraint phase. Data analysis was conducted as described previously in detail (Carnevali et al., 2013a). Values are reported as means \pm s.e.m. ${ }^{*}$ and ${ }^{\#}$ indicate a significant difference between HAB and $\mathrm{LAB}$ rats $(p<0.05$ and $p<0.01$, respectively; Student's $t$-test). 
submitted to intermittent episodes of restraint stress showed a prolonged increase in resting vagal drive in the days that followed the end of the stress period, as indicated by the increase in the vagal index RMSSD. Likewise, in another study, sub-chronically stressed rats ( 5 days of footsocks) exhibited a substantial increase in resting vagal tone that lasted well beyond the duration of the stressor (Carnevali et al., 2011). This peculiar phenomenon might be called "enduring vagal rebound" or "persistent vagal rebound" (Carnevali et al., 2011). In the literature, the term "vagal rebound" usually refers to a short-term vagal hyperactivity following a stressor, a sympathetic overdrive or reperfusion following acute myocardial infarction (Chiladakis et al., 2001; Mezzacappa et al., 2001). In this study (Carnevali et al., 2011), it was a relatively persistent, long-term consequence of repeated stress exposure, whose underlying neurobiological determinants have yet to be determined. However, it appears that this enduring vagal rebound is corticosterone- and serotonin-independent, as it was not prevented by metyrapone (inhibitor of corticosteroid synthesis) or fluoxetine (serotonin-selective reuptake inhibitor) treatments (Carnevali et al., 2011). Such sustained vagal activation after repeated stress exposure has been interpreted as a sign of adaptation, a transient compensatory phenomenon that initially overcomes the commonly observed stress-induced sympathetic hyperactivity (Carnevali et al., 2011). This adaptation might fail after a more prolonged exposure to stress and/or exposure to a more severe stressor, leading the organism to a maladaptive phase of vagal withdrawal and sympathetic dominance. Indeed, like humans, the most pervasive stressors in rats fall within the social domain (Bjorkqvist, 2001; Sgoifo et al., 2014). On this regard, the resident-intruder stress paradigm (Miczek, 1979) is regarded as an ethologically relevant model of psychosocial stress in rats, which involves subjecting a male intruder rat to aggressive threats and overt attacks by an unfamiliar male rat (resident) in the resident's home cage. This stress paradigm has recently been applied to study the shared pathophysiology that links stress-related psychological disorders such as anxiety and depression with cardiovascular disease (Carnevali et al., 2012b, 2013b; Wood et al., 2012; Sevoz-Couche et al., 2013). This raises another important issue that will be discussed in the next sections: the interplay between stress and related psychological disorders in the modulation of resting vagal tone.

\section{ANXIETY}

Cardiac autonomic function in rats displaying symptoms of stress-evoked anxiety was investigated in a study conducted by Sevoz-Couche et al. (2013). In this study, HRV analysis was conducted in rats submitted to intermittent daily episodes of social defeat, following a classical resident-intruder paradigm. Five days after the last defeat, stressed rats showed symptoms of an anxiety-like behavior that were accompanied by signs of reduced vagal modulation of resting $H R$, as suggested by the decrease in the vagal indexes RMSSD and HF power (SevozCouche et al., 2013). Interestingly, such reduction in cardiac vagal tone was prevented by inhibition of the dorsomedial hypothalamus (DMH) with muscimol and the blockade of the NTS $5-\mathrm{HT}_{3}$ receptors with granisetron. During acute stress, the DMH acts on the rostral cuneiform nucleus that, in turn, activates the rostral periacqueductal gray (Netzer et al., 2011). Downstream to this structure, serotonin $(5-\mathrm{HT})$ is released to activate $5-\mathrm{HT}_{3}$ receptors that are localized presynaptically on NTS vagal afferents (Leslie et al., 1990) (Figure 1). When activated, these receptors trigger glutamatergic activation of local GABAergic interneurons that project to the NAmb on pre-ganglionic vagal neurons, thereby inhibiting vagal activity (Loewy, 1990) (Figure 1). Therefore, it is reasonable to hypothesize that chronic activation of $5-\mathrm{HT}_{3}$ receptors in the NTS due to overactivity of $5-\mathrm{HT}$ in this region and/or hypersensitivity of $5-\mathrm{HT}_{3}$ receptors is at the origin of vagal tone impairment in repeatedly stressed animals. These findings highlight the role of $\mathrm{DMH}$ and NTS in vagal tone impairment following repeated social challenge.

The alterations in cardiac vagal tone that have been described in this animal model of stress-evoked anxiety may also characterize other forms of anxiety. Addressing this issue, we have recently investigated cardiac autonomic function in a rat model of trait anxiety, namely Wistar rats selectively bred for either high (HAB) or low (LAB) anxiety-related behavior (Carnevali et al., 2014). The $\mathrm{HAB} / \mathrm{LAB}$ rats have been proved to display robust and consistent differences in their level of baseline anxiety (Landgraf and Wigger, 2002) and therefore represent a valid and reliable model for investigating the autonomic correlates of extremes in anxietyrelated behavior. HAB rats clearly displayed a lower vagal modulation of resting $\mathrm{HR}$ (indexed by RMSSD and HF values) compared to $\mathrm{LAB}$ rats during both the light/inactive and dark/active phases of the daily cycle (Figure 4). One of the most puzzling findings was that, despite this evident difference in resting vagal tone, $\mathrm{HAB}$ and $\mathrm{LAB}$ rats had similar HR values (Figure 4). This is indicative of the fact that simple measurements of HR do not necessarily provide accurate insights into the functional regulatory characteristics of the autonomic nervous system. Indeed, mean HR values are indicative of the net effects of sympathetic and vagal influences on cardiac activity, which often result from a combination of concurrent changes in activity within both branches (Berntson et al., 1991). Therefore, it is reasonable to hypothesize that the reduced cardiac vagal tone observed in $\mathrm{HAB}$ rats was coupled with a decreased cardiac sympathetic influence on the sinoatrial node compared to $\mathrm{LAB}$ rats. Supporting this view, HAB and LAB rats showed similar LF to HF ratio (index of sympatho-vagal balance), suggesting that vagal and sympathetic influences on cardiac pacemaker activity were equally balanced in the two groups, leading to similar HR values (Figure 4). When tested under stress conditions (i.e., restraint test), $\mathrm{HAB}$ rats showed reduced HR stress responsiveness compared to LAB counterparts, as suggested by the values of the area under the response curve above baseline (AUC) (Figure 5). In HAB rats, this phenomenon appeared to be related to a reduced vagal flexibility, namely a smaller vagal withdrawal in response to stress, and was coupled with a tendentially larger vulnerability to ventricular arrhythmias compared to LAB counterparts (Figure 5). These findings support the view that a low tonic vagal modulation of HR in HAB rats may have determined an inability to flexibly generate adequate cardiac responses to environmental demands. Furthermore, these findings provide a strong basis for future mechanistic investigation aimed at defining, using this rat model, the central neural determinants of vagal 


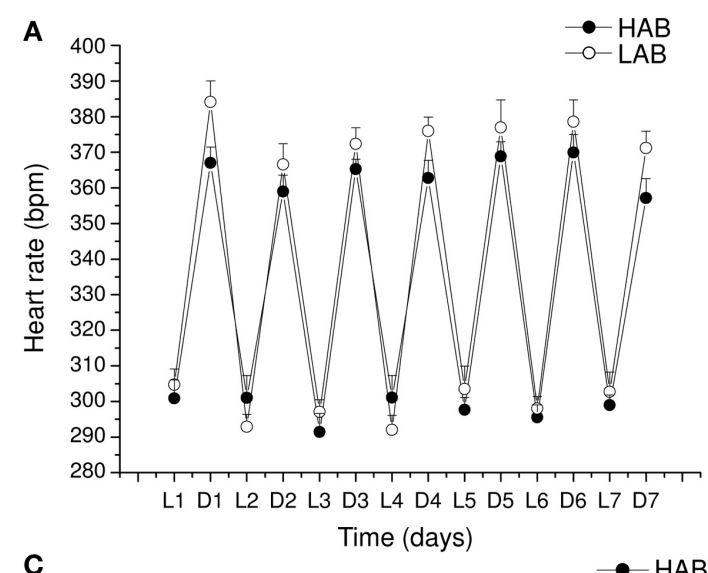

C

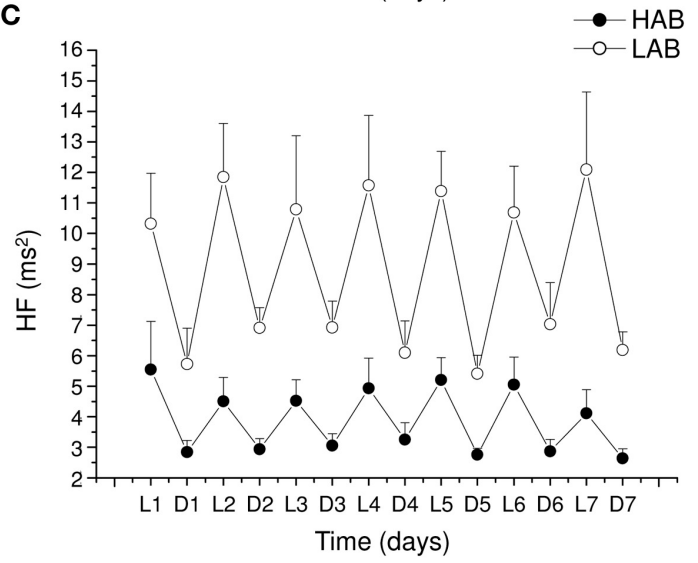

FIGURE 4 | Daily rhythms of (A) heart rate, (B) RMSSD, (C) spectral power in HF band $(0.75-2.5 \mathrm{~Hz})$ and (D) LF $(0.2-0.75 \mathrm{~Hz})$ to HF ratio in 4-month-old Wistar rats selectively bred for either high (HAB, $\boldsymbol{n}=10$ ) or low (LAB, $n=10$ ) anxiety-related behavior. These values (reported as means \pm SEM) were obtained by averaging multiple 2-min
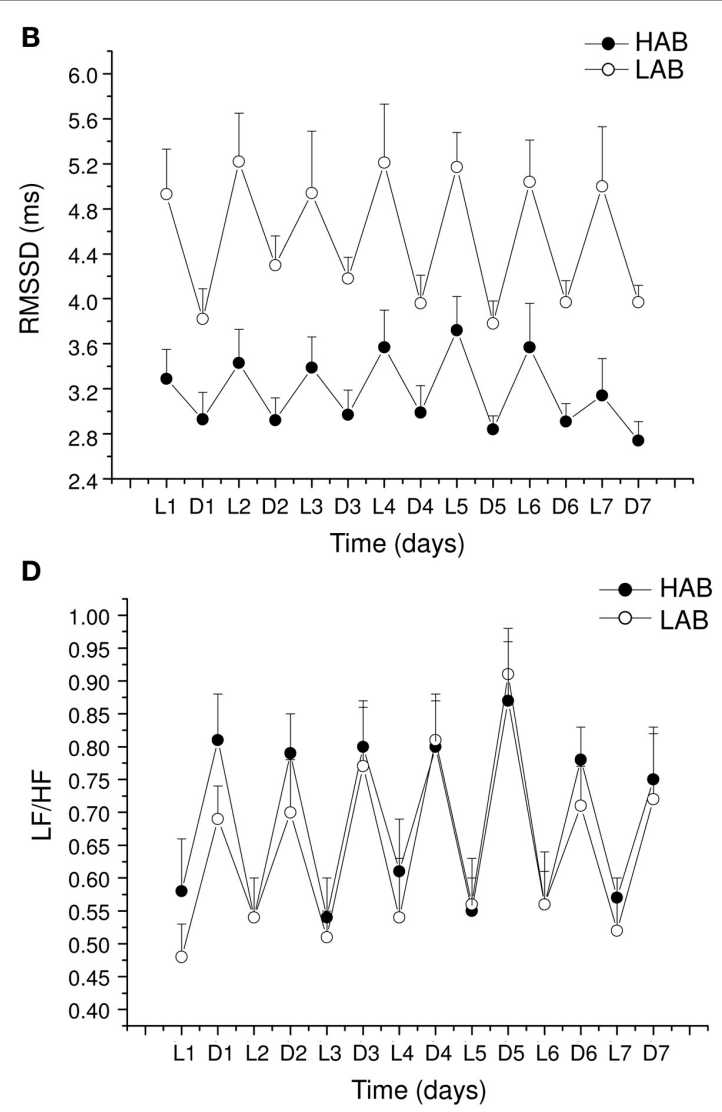

segments acquired every hour during the $12 \mathrm{~h}$-light and $12 \mathrm{~h}$-dark phases, as previously described in detail (Carnevali et al., 2014). Results of two-way ANOVA for repeated measures: group difference for RMSSD $(F=16.4, p<0.01)$ and $\mathrm{HF}(F=17.48, p<0.01)$ values. Modified from Carnevali et al. (2014). control impairment in individuals with high levels of baseline anxiety.

\section{DEPRESSION}

The complex interplay among social stress, depression and autonomic neural modulation of HR was investigated in a rat model of social stress by Wood et al. (2012). Rats exposed to 7 consecutive days of social defeat displayed symptoms of a depressive-like state. Forty eight hours after the final social defeat stress, depressed rats showed reduced HRV and signs of sympathetic predominance (increased LF to HF ratio). It was not determined whether such autonomic imbalance was due to a decrease in vagal tone and/or an increase in sympathetic tone. Similar changes in cardiac autonomic neural outflow were observed in rats submitted to a chronic mild stress model of depression (Grippo et al., 2004, 2006). Importantly, such abnormal modulation of resting HR in depressed rats was partially abolished by fluoxetine treatment (Grippo et al., 2006), suggesting a potential involvement of 5-HT neurotransmission in mediating autonomic changes in depressed individuals. Supporting this view, a study conducted by Hildreth et al. (2008) provided evidence of resting vagal tone impairment in a genetic rat model of depression (i.e., the Flinders-Sensitive
Line rat) that was related to abnormal serotonergic control of vagal modulation of HR. Human studies indicate that brain 5-HT levels (Mann and Stoff, 1997) and 5-HT receptor function, particularly the $5-\mathrm{HT}_{1 \mathrm{~A}}$ receptors (Parsey et al., 2006), are abnormal in depression. Importantly, it has been demonstrated that chronic social defeat downregulates the $5-\mathrm{HT}_{1 \mathrm{~A}}$ receptor in the rat brain (Kieran et al., 2010). The $5-\mathrm{HT}_{1 \mathrm{~A}}$ receptors play an important role in inhibiting sympathetic neurons located in the medullary raphe area that activates the heart during stress (Nalivaiko, 2006; Nalivaiko and Sgoifo, 2009). In addition to sympathoinhibition, activation of $5-\mathrm{HT}_{1 \mathrm{~A}}$ receptors may have vagomimetic effects (Ngampramuan et al., 2008; Dutschmann et al., 2009; Carnevali et al., 2012a). Indeed, given that vagal preganglionic neurons in the NAmb are under tonic inhibition by GABA-ergic interneurons that express $5-\mathrm{HT}_{1 \mathrm{~A}}$ receptors, activation of such inhibitory $5-\mathrm{HT}_{1 \mathrm{~A}}$ receptors may lead to disinhibition of cardiomotor vagal neurons and consequently increase cardiac vagal tone (Jordan, 2005) (Figure 1). Therefore, a decreased density/function of 5$\mathrm{HT}_{1 \mathrm{~A}}$ receptors in these areas may be at the origin of the imbalance in the autonomic neural modulation of resting HR in chronically stressed and depressed individuals. Further work is required in order to determine whether serotonergic mechanisms 


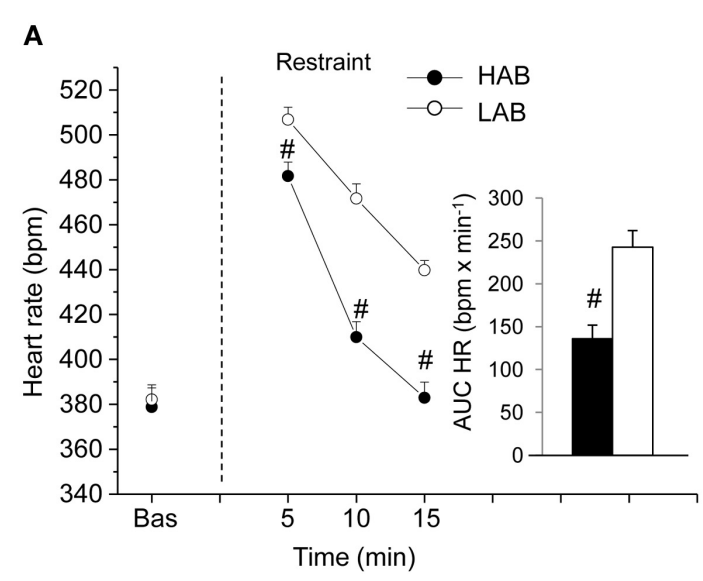

C

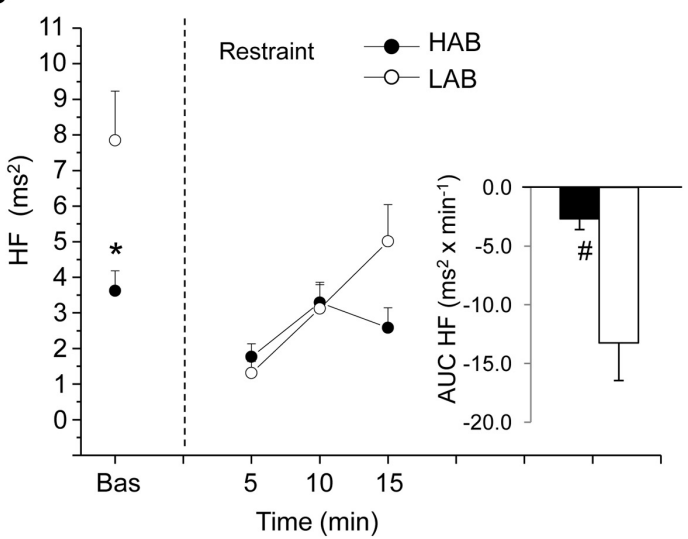

FIGURE 5 | Cardiac response to a restraint stress test in 4-mont-old Wistar rats selectively bred for either high $(\mathrm{HAB}, n=10)$ or low (LAB, $\boldsymbol{n}=\mathbf{1 0}$ ) anxiety-related behavior. Panels (A-C) show the time course of changes in heart rate, RMSSD values and high-frequency $(H F$, $0.75-2.5 \mathrm{~Hz}$ ) spectral power in baseline conditions (bas, $30 \mathrm{~min}$ ) and during the restraint test $(15 \mathrm{~min})$, respectively. Each point during the restraint phase is the mean of 5-min intervals. Inner graphs in (A-C)
B

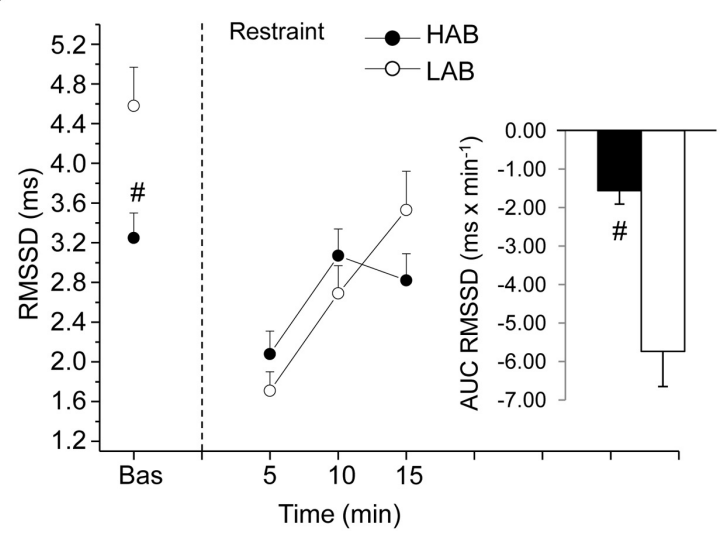

D

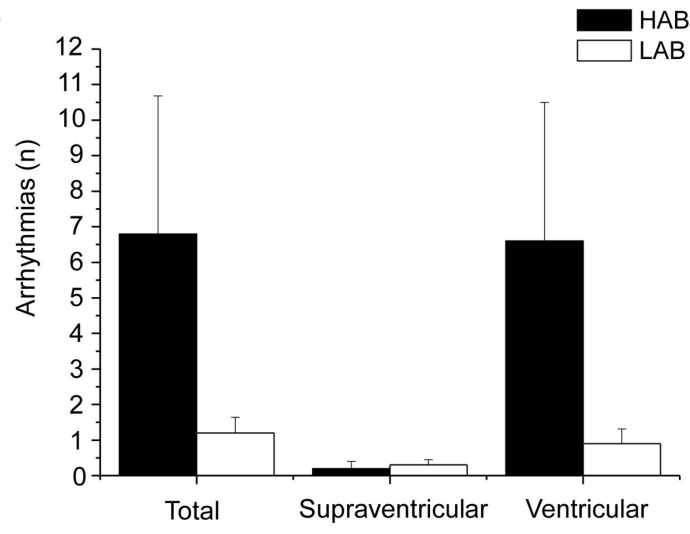

represent the area under the response time curve above baseline (AUC) of heart rate, RMSSD and HF values during the restraint phase. Panel (D) illustrates the incidence of cardiac arrhythmias during the restraint phase. Values are reported as means \pm s.e.m. * and \# indicate a significant difference between $\mathrm{HAB}$ and $\mathrm{LAB}$ rats $(p<0.05$ and $p<0.01$, respectively; Student's $t$-test). Modified with permission from Carnevali et al. (2014). do contribute to driving the changes in autonomic modulation of resting HR in rat models of depression.

\section{AGGRESSIVENESS}

The association between personality traits (i.e., aggressiveness) and autonomic neural control of resting HR was the focus of one of our recent investigations (Carnevali et al., 2013a). In this study, high-aggressive (HA) and non-aggressive (NA) rats were selected from a population of adult male Wild-type rats on the basis of their latency time to attack a male intruder in a classical residentintruder test performed on 3 consecutive days (HA: mean attack latency <90 s; NA: no overt aggression during the three tests, each lasting $600 \mathrm{~s}$ ) (Koolhaas et al., 2013). As suggested by RMSSD and HF power indexes, HA rats exhibited lower levels of vagal modulation of resting $\mathrm{HR}$ during both the light/inactive and dark/active active phases of the daily cycle (Figure 6). However, despite different levels of resting vagal tone, HA and NA rats had similar HR values (Figure 6). Similarly to what has been argued above, it has been hypothesized that the reduced cardiac vagal tone observed in HA rats was coupled with a decreased sympathetic influence on sinoatrial node activity compared to NA rats. Consequently, vagal and sympathetic influences were equally balanced in the two groups (LF to HF ratio), leading to similar HR values (Figure 6) (Carnevali et al., 2013a). When tested under stress conditions (i.e., restraint and psychosocial stress test), HA and NA rats showed similar tachycardic responses. However, under these conditions HA rats displayed lower vagal antagonism and larger incidence of tachyarrhythmias compared to NA rats (Figure 7) (Carnevali et al., 2013a). In addition, injection of beta adrenergic agonist isoproterenol provoked a much larger incidence of ventricular tachyarrhythmias in HA rats compared to NA counterparts (Carnevali et al., 2013a) (Figure 7). The results of this study support the view that low levels of vagal modulation of resting HR are associated with arrhythmia susceptibility that may predict vulnerability to cardiac morbidity and mortality. Future mechanistic experiments using this rat model are needed in order to determine the neural determinants of vagal control impairment in aggressive individuals. 

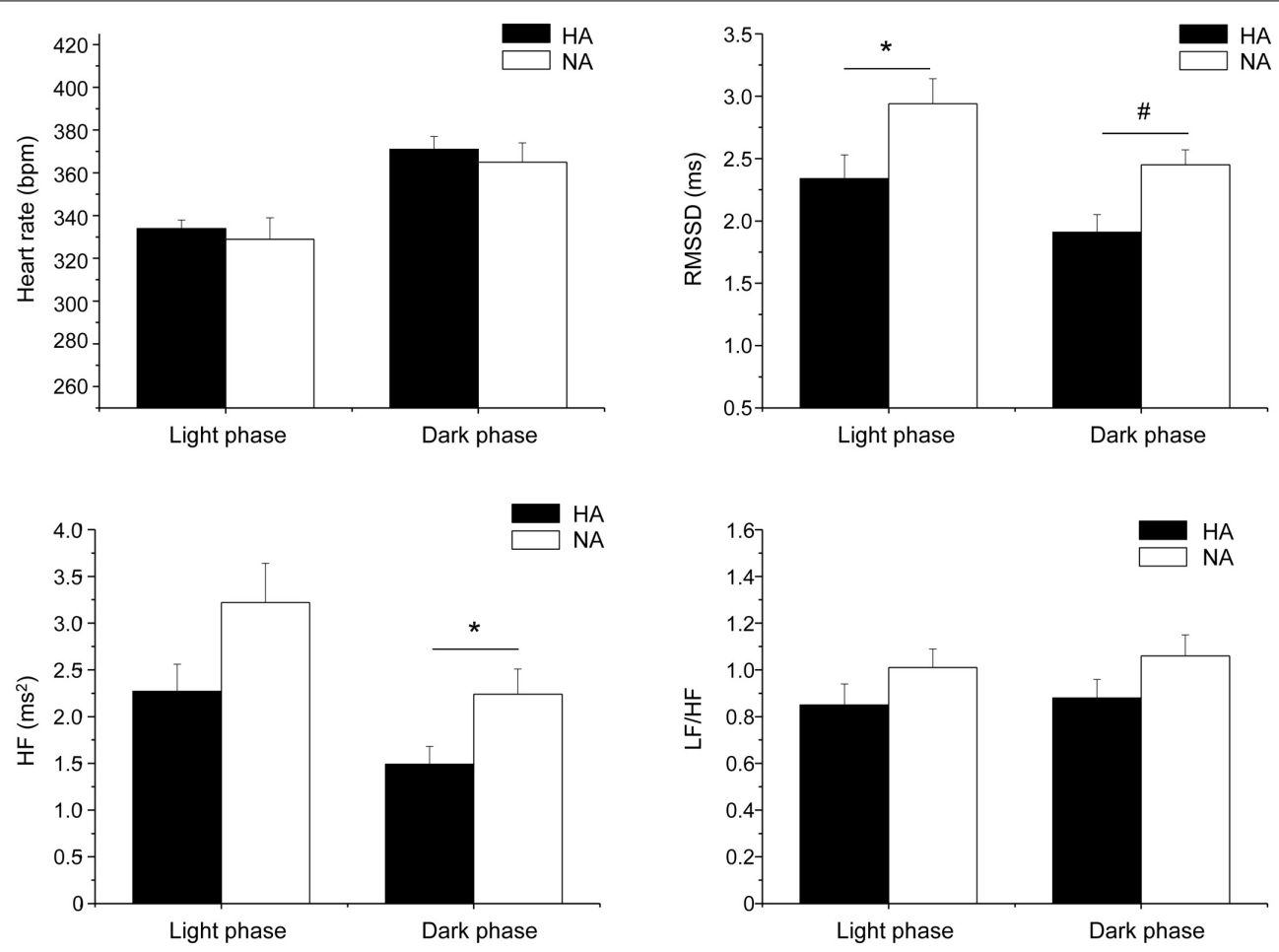

FIGURE 6 | Daily rhythms of heart rate, RMSSD, spectral power in HF band $(0.75-2.5 \mathrm{~Hz})$ and $\mathrm{LF}(0.2-0.75 \mathrm{~Hz})$ to $\mathrm{HF}$ ratio in high-aggressive (HA, $\boldsymbol{n}=\mathbf{1 0}$ ) and non-aggressive (NA, $\boldsymbol{n}=\mathbf{1 0}$ ) Wild-type rats. For the 12 hours-light and 12 hours-dark phases, values are reported as means \pm s.e.m.

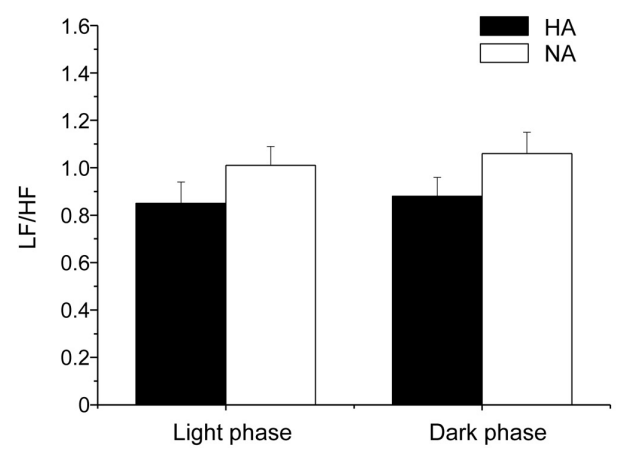

of data obtained by averaging multiple 2-min segments acquired every hour over a period of 6 days. ${ }^{*}$ and ${ }^{\#}$ indicate a significant difference between HAB and $L A B$ rats (Student's $t$-test, $p<0.05$ and $p<0.01$, respectively). Modified with permission from Carnevali et al. (2013a).

\section{EFFECTS OF PHYSICAL EXERCISE ON VAGAL MODULATION OF RESTING HR}

Human studies provide evidence that regular physical exercise increases life expectancy in healthy individuals and reduces cardiac-related events in patients with coronary heart disease and heart failure (Rosenwinkel et al., 2001; Buch et al., 2002). The cardioprotective effects of physical training may be mediated, at least in part, by an increase in vagal modulation of resting HR (Crimi et al., 2009). However, central neural mechanisms that underlie these exercise-induced effects on vagal tone are not well understood. Cardiac autonomic adaptation induced by physical training has been subject of research in several carefully designed and rigorously conducted rat studies. These studies reported a clear decrease in resting HR in rats submitted to training with aerobic exercises (i.e., swimming, running) (Medeiros et al., 2004; Rossi et al., 2009; Souza et al., 2009; Sant'Ana et al., 2011; Neto et al., 2013). The effect of the autonomic nervous system in mediating training-induced resting bardycardia was investigated by means of (i) pharmacological approaches (after cardiac muscarinic and adrenergic blockade) and (ii) HRV analysis. Resting bradycardia after exercise training was mainly explained by a vagal effect (Medeiros et al., 2004) or by a reduction in intrinsic HR accompanied by a moderate increase in vagal modulation (indexed by HF spectral power values) (Rossi et al., 2009; Souza et al., 2009; Sant'Ana et al., 2011; Neto et al., 2013).

One possible limitation of these studies is that they applied protocols of forced exercise (treadmill or swimming). In doing so, the effects of physical exercise per se on cardiac autonomic function might have been confounded by the effects of accompanying psychological stress (the effects of repeated stress exposure on vagal modulation have been discussed before). On this regard, an elegant study conducted by Beig et al. (2011) investigated the effects of voluntary running on cardiac autonomic function. This study addressed another important issue: that is, whether the effects of voluntary exercise on autonomic function were long-lasting. This question is of major relevance, since loss of exercise-induced cardioprotection has been described soon after exercise cessation (Lin and Horvath, 1972). Rats submitted to a protocol of voluntary exercise exhibited resting bradycardia associated with increased vagal modulation (indexed by HF spectral power values) (Beig et al., 2011). Importantly, these effects persisted 10-12 days after termination of the training protocol, suggesting that voluntary exercise has an enduring effect on resting vagal tone.

Interestingly, voluntary training did not affect stress-induced tachycardia, but augmented resistance to cardiac arrhythmias, as evidenced by the higher doses of the proarrhythmic drug aconitine needed to provoke arrhythmic effects in trained rats (Beig et al., 2011). Such antiarrhythmic effect of exercise training seems to reflect electrophysiological changes (i.e., prolongation of the effective refractory period) induced by long-lasting increase 

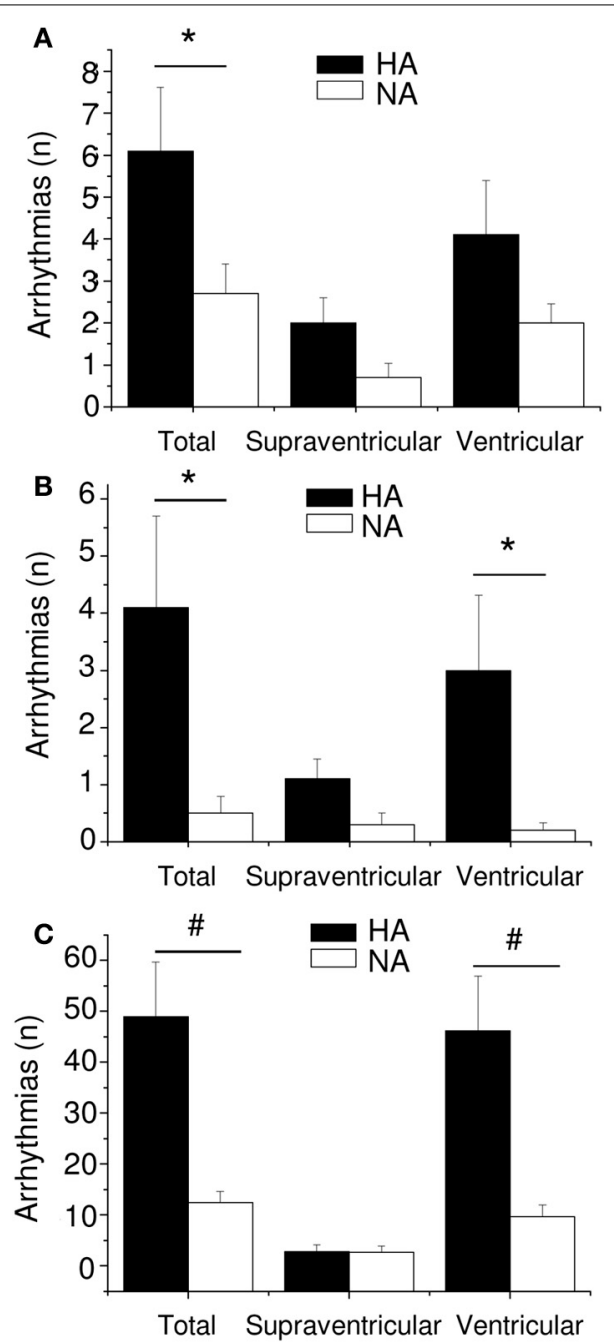

FIGURE 7 | Incidence of arrhythmias in high-aggressive (HA, $n=10$ ) and non-aggressive (NA, $n=10$ ) Wild-type rats during a restraint test (panel A), a psychosocial stress test (panel B) and following $\boldsymbol{\beta}$-adrenoceptor pharmacological stimulation with isoproterenol (panel C). Values are reported as mean \pm s.e.m. of number of events (n) per 15-min recording period. * and ${ }^{\#}$ indicate a significant difference between $\mathrm{HA}$ and NA rats ( $p<0.05$ and $p<0.01$, respectively). Reproduced with permission from Carnevali et al. (2013a).

in vagal outflow in trained rats (Beig et al., 2011). This suggests that the benefits of increased resting vagal tone induced by exercise training may be attributed to (i) an HR-lowering effect and (ii) other parasympathetic effects on the electrophysiological properties of the myocardium. However, the mechanistic links whereby physical training provokes changes in resting vagal outflow are currently unknown. One hypothesis is that exercise might reduce tonic $\mathrm{GABA}_{\mathrm{A}}$ ergic inhibition of neurons in the NTS involved in HR control (Figure 1), therefore increasing vagal influences on cardiac peacemaker activity (Mueller and Hasser, 2006). Given that physical exercise increases central 5-HT synthesis (Blomstrand et al., 1989), and that central 5-HT increases vagal modulation in conscious rats (Ngampramuan et al., 2008), it is tempting to speculate that activation of inhibitory $5-\mathrm{HT}_{1 \mathrm{~A}}$ receptors located on GABA-ergic interneurons in the Namb might mediate disinhibition of cardiomotor vagal neurons in that area (Figure 1). Further work is required in order to (i) evaluate potential correlations between duration/intensity of voluntary exercise and effects on resting vagal tone and (ii) provide a more comprehensive understanding of central neural mechanisms underlying exercise-induced vagal tone enhancement.

\section{CONCLUDING REMARK}

The influence of vagal tone on resting HR is highly variable among individuals. Several psychosocial and physiological conditions are thought to contribute significantly to this large interindividual variability. From the data summarized in this paper, it is quite evident that rat studies can be extremely useful for investigating (i) the effects of stress, psychosocial factors, and physical exercise on vagal modulation of resting $\mathrm{HR}$, and (ii) the consequences of such effects on cardiac stress reactivity and arrhythmia vulnerability. Moreover, the results of these studies have provided preliminary insights into the central neural mechanisms underlying vagal tone impairment/enhancement, which may be exploited by future experiments aimed at developing pharmacological approaches for enhancing vagal activity and cardioprotection.

\section{REFERENCES}

Albus, C. (2010). Psychological and social factors in coronary heart disease. Ann. Med. 42, 487-494. doi: 10.3109/07853890.2010.515605

Beauchaine, T. (2001). Vagal tone, development, and Gray's motivational theory: toward an integrated model of autonomic nervous system functioning in psychopathology. Dev. Psychopathol. 13, 183-214. doi: 10.1017/S0954579401002012

Beig, M. I., Callister, R., Saint, D. A., Bondarenko, E., Walker, F. R., Day, T. A., et al. (2011). Voluntary exercise does not affect stress-induced tachycardia, but improves resistance to cardiac arrhythmias in rats. Clin. Exp. Pharmacol. Physiol. 38, 19-26. doi: 10.1111/j.1440-1681.2010.05456.x

Berntson, G. G., Bigger, J. T. Jr., Eckberg, D. L., Grossman, P., Kaufmann, P. G., Malik, M., et al. (1997). Heart rate variability: origins, methods, and interpretive caveats. Psychophysiology 34, 623-648. doi: 10.1111/j.1469-8986.1997.tb02140.x

Berntson, G. G., Cacioppo, J. T., and Quigley, K. S. (1991). Autonomic determinism: the modes of autonomic control, the doctrine of autonomic space, and the laws of autonomic constraint. Psychol. Rev. 98, 459-487. doi: 10.1037/0033295X.98.4.459

Bigger, J. T. Jr., Steinman, R. C., Rolnitzky, L. M., Fleiss, J. L., Albrecht, P., and Cohen, R. J. (1996). Power law behavior of RR-interval variability in healthy middle-aged persons, patients with recent acute myocardial infarction, and patients with heart transplants. Circulation 93, 2142-2151. doi: 10.1161/01.CIR.93.12.2142

Billman, G. E. (2011). Heart rate variability - a historical perspective. Front. Physiol. 2:86. doi: 10.3389/fphys.2011.00086

Bjorkqvist, K. (2001). Social defeat as a stressor in humans. Physiol. Behav. 73, 435-442. doi: 10.1016/S0031-9384(01)00490-5

Blomstrand, E., Perrett, D., Parry-Billings, M., and Newsholme, E. A. (1989). Effect of sustained exercise on plasma amino acid concentrations and on 5hydroxytryptamine metabolism in six different brain regions in the rat. Acta Physiol. Scand. 136, 473-481. doi: 10.1111/j.1748-1716.1989.tb08689.x

Blumenthal, J. A., Sherwood, A., Rogers, S. D., Babyak, M. A., Doraiswamy, P. M., Watkins, L., et al. (2007). Understanding prognostic benefits of exercise and antidepressant therapy for persons with depression and heart disease: the UPBEAT study-rationale, design, and methodological issues. Clin. Trials 4, 548-559. doi: 10.1177/1740774507083388

Bryniarski, L., Kawecka-Jaszcz, K., Bacior, B., Grodecki, J., and Rajzer, M. (1997) Effect of exercise rehabilitation on heart rate variability in hypertensives after myocardial infarction. J. Hypertens. 15, 1739-1743. doi: 10.1097/00004872199715120-00082 
Buch, A. N., Coote, J. H., and Townend, J. N. (2002). Mortality, cardiac vagal control and physical training-what's the link? Exp. Physiol. 87, 423-435. doi: 10.1111/j.1469-445X.2002.tb00055.x

Carnevali, L., Bondarenko, E., Sgoifo, A., Walker, F. R., Head, G. A., Lukoshkova, E. V., et al. (2011). Metyrapone and fluoxetine suppress enduring behavioral but not cardiac effects of subchronic stress in rats. Am. J. Physiol. Regul. Integr. Comp. Physiol. 301, R1123-1131. doi: 10.1152/ajpregu.00273.2011

Carnevali, L., Mastorci, F., Audero, E., Graiani, G., Rossi, S., Macchi, E., et al. (2012a). Stress-induced susceptibility to sudden cardiac death in mice with altered serotonin homeostasis. PLOS ONE 7:e41184. doi: 10.1371/journal.pone.0041184

Carnevali, L., Mastorci, F., Graiani, G., Razzoli, M., Trombini, M., Pico-Alfonso, M. A., et al. (2012b). Social defeat and isolation induce clear signs of a depressionlike state, but modest cardiac alterations in wild-type rats. Physiol. Behav. 106 , 142-150. doi: 10.1016/j.physbeh.2012.01.022

Carnevali, L., Trombini, M., Graiani, G., Madeddu, D., Quaini, F., Landgraf, R., et al. (2014). Low vagally-mediated heart rate variability and increased susceptibility to ventricular arrhythmias in rats bred for high anxiety. Physiol. Behav. 128C, 16-25. doi: 10.1016/j.physbeh.2014.01.033

Carnevali, L., Trombini, M., Porta, A., Montano, N., De Boer, S. F., and Sgoifo, A. (2013a). Vagal withdrawal and susceptibility to cardiac arrhythmias in rats with high trait aggressiveness. PLoS ONE 8:e68316. doi: 10.1371/journal.pone.0068316

Carnevali, L., Trombini, M., Rossi, S., Graiani, G., Manghi, M., Koolhaas, J. M., et al. (2013b). Structural and electrical myocardial remodeling in a rodent model of depression. Psychosom. Med. 75, 42-51. doi: $10.1097 /$ PSY.0b013e318276cb0d

Cheng, Z., and Powley, T. L. (2000). Nucleus ambiguus projections to cardiac ganglia of rat atria: an anterograde tracing study. J. Comp. Neurol. 424, 588-606. doi: 10.1002/1096-9861(20000904)424:4<588::AID-CNE3>3.0.CO;2-7

Cheng, Z., Powley, T. L., Schwaber, J. S., and Doyle, F. J. 3rd. (1999). Projections of the dorsal motor nucleus of the vagus to cardiac ganglia of rat atria: an anterograde tracing study. J. Comp. Neurol. 410, 320-341.

Chiladakis, J. A., Pashalis, A., Patsouras, N., and Manolis, A. S. (2001). Autonomic patterns preceding and following accelerated idioventricular rhythm in acute myocardial infarction. Cardiology 96, 24-31. doi: 10.1159/000047382

Crimi, E., Ignarro, L. J., Cacciatore, F., and Napoli, C. (2009). Mechanisms by which exercise training benefits patients with heart failure. Nat. Rev. Cardiol. 6, 292-300. doi: 10.1038/nrcardio.2009.8

Dutschmann, M., Waki, H., Manzke, T., Simms, A. E., Pickering, A. E., Richter, D. W., et al. (2009). The potency of different serotonergic agonists in counteracting opioid evoked cardiorespiratory disturbances. Philos. Trans. R. Soc. Lond. B Biol. Sci. 364, 2611-2623. doi: 10.1098/rstb.2009.0076

El-Sheikh, M., Harger, J., and Whitson, S. M. (2001). Exposure to interparental conflict and children's adjustment and physical health: the moderating role of vagal tone. Child Dev. 72, 1617-1636. doi: 10.1111/1467-8624.00369

Esler, M. (1992). The autonomic nervous system and cardiac arrhythmias. Clin. Auton. Res. 2, 133-135. doi: 10.1007/BF01819669

Friedman, B. H., and Thayer, J. F. (1998). Anxiety and autonomic flexibility: a cardiovascular approach. Biol. Psychol. 47, 243-263. doi: 10.1016/S03010511(97)00027-6

Fu, Q., and Levine, B. D. (2013). Exercise and the autonomic nervous system. Handb. Clin. Neurol. 117, 147-160. doi: 10.1016/B978-0-444-53491-0.00013-4

Gorman, J. M., and Sloan, R. P. (2000). Heart rate variability in depressive and anxiety disorders. Am. Heart J. 140, 77-83. doi: 10.1067/mhj.2000.109981

Grippo, A. J., Beltz, T. G., Weiss, R. M., and Johnson, A. K. (2006). The effects of chronic fluoxetine treatment on chronic mild stress-induced cardiovascular changes and anhedonia. Biol. Psychiatry 59, 309-316. doi: 10.1016/j.biopsych.2005.07.010

Grippo, A. J., Santos, C. M., Johnson, R. F., Beltz, T. G., Martins, J. B., Felder, R. B., et al. (2004). Increased susceptibility to ventricular arrhythmias in a rodent model of experimental depression. Am. J. Physiol. Heart Circ. Physiol. 286, H619-H626. doi: 10.1152/ajpheart.00450.2003

Hildreth, C. M., Padley, J. R., Pilowsky, P. M., and Goodchild, A. K. (2008). Impaired serotonergic regulation of heart rate may underlie reduced baroreflex sensitivity in an animal model of depression. Am. J. Physiol. Heart Circ. Physiol. 294, H474-H480. doi: 10.1152/ajpheart.01009.2007

Huikuri, H. V., Makikallio, T. H., Airaksinen, K. E., Seppanen, T., Puukka, P., Raiha, I. J., et al. (1998). Power-law relationship of heart rate variability as a predictor of mortality in the elderly. Circulation 97, 2031-2036. doi: 10.1161/01.CIR.97.20.2031

Huikuri, H. V., Makikallio, T. H., Peng, C. K., Goldberger, A. L., Hintze, U., and Moller, M. (2000). Fractal correlation properties of R-R interval dynamics and mortality in patients with depressed left ventricular function after an acute myocardial infarction. Circulation 101, 47-53. doi: 10.1161/01.CIR.101.1.47

Iellamo, F., Legramante, J. M., Massaro, M., Raimondi, G., and Galante, A. (2000). Effects of a residential exercise training on baroreflex sensitivity and heart rate variability in patients with coronary artery disease: a randomized, controlled study. Circulation 102, 2588-2592. doi: 10.1161/01.CIR.102. 21.2588

Jordan, D. (2005). Vagal control of the heart: central serotonergic (5-HT) mechanisms. Exp. Physiol. 90, 175-181. doi: 10.1113/expphysiol.2004.029058

Jose, A. D., and Collison, D. (1970). The normal range and determinants of the intrinsic heart rate in man. Cardiovasc. Res. 4, 160-167. doi: 10.1093/cvr/4.2.160

Kieran, N., Ou, X. M., and Iyo, A. H. (2010). Chronic social defeat downregulates the 5-HT1A receptor but not Freud-1 or NUDR in the rat prefrontal cortex. Neurosci. Lett. 469, 380-384. doi: 10.1016/j.neulet.2009.12.032

Kleiger, R. E., Stein, P. K., Bosner, M. S., and Rottman, J. N. (1992). Time domain measurements of heart rate variability. Cardiol. Clin. 10, 487-498.

Kok, B. E., and Fredrickson, B. L. (2010). Upward spirals of the heart: autonomic flexibility, as indexed by vagal tone, reciprocally and prospectively predicts positive emotions and social connectedness. Biol. Psychol. 85, 432-436. doi: 10.1016/j.biopsycho.2010.09.005

Koolhaas, J. M., Coppens, C. M., De Boer, S. F., Buwalda, B., Meerlo, P., and Timmermans, P. J. (2013). The resident-intruder paradigm: a standardized test for aggression, violence and social stress. J. Vis. Exp. 4:e4367. doi: 10.3791/4367

Landgraf, R., and Wigger, A. (2002). High vs low anxiety-related behavior rats: an animal model of extremes in trait anxiety. Behav. Genet. 32, 301-314. doi: 10.1023/A:1020258104318

La Rovere, M. T., Bigger, J. T. Jr., Marcus, F. I., Mortara, A., and Schwartz, P. J. (1998). Baroreflex sensitivity and heart-rate variability in prediction of total cardiac mortality after myocardial infarction. ATRAMI (Autonomic Tone and Reflexes After Myocardial Infarction) Investigators. Lancet 351, 478-484. doi: 10.1016/S0140-6736(97)11144-8

Leslie, R. A., Reynolds, D. J., Andrews, P. L., Grahame-Smith, D. G., Davis, C. J., and Harvey, J. M. (1990). Evidence for presynaptic 5-hydroxytryptamine3 recognition sites on vagal afferent terminals in the brainstem of the ferret. Neuroscience 38, 667-673. doi: 10.1016/0306-4522(90)90060-H

Levy, M. N. (1971). Sympathetic-parasympathetic interactions in the heart. Circ Res. 29, 437-445. doi: 10.1161/01.RES.29.5.437

Levy, M. N., and Schwartz, P. J. (1994). Vagal Control of the Heart: Experimental Basis and Clinical Implications. Armonk, NY: Futura Publishing Co.

Lin, Y. C., and Horvath, S. M. (1972). Autonomic nervous control of cardiac frequency in the exercise-trained rat. J. Appl. Physiol. 33, 796-799.

Loewy, A. D. (1990). "Anatomy of the autonomic nervous system: an overview," in Central Regulation of the Autonomic Function, eds A. D. Loewy and K. M. Spyer (New York, NY: Oxford University Press), 1-16.

Lombardi, F., Sandrone, G., Mortara, A., Torzillo, D., La Rovere, M. T., Signorini, M. G., et al. (1996). Linear and nonlinear dynamics of heart rate variability after acute myocardial infarction with normal and reduced left ventricular ejection fraction. Am. J. Cardiol. 77, 1283-1288. doi: 10.1016/S0002-9149(96) 00193-2

Lucini, D., Di Fede, G., Parati, G., and Pagani, M. (2005). Impact of chronic psychosocial stress on autonomic cardiovascular regulation in otherwise healthy subjects. Hypertension 46, 1201-1206. doi: 10.1161/01.HYP.0000185147.32385.4b

Makikallio, T. H., Hoiber, S., Kober, L., Torp-Pedersen, C., Peng, C. K., Goldberger, A. L., et al. (1999). Fractal analysis of heart rate dynamics as a predictor of mortality in patients with depressed left ventricular function after acute myocardial infarction. TRACE Investigators. TRAndolapril Cardiac Evaluation. Am. J Cardiol. 83, 836-839. doi: 10.1016/S0002-9149(98)01076-5

Makikallio, T. H., Seppanen, T., Airaksinen, K. E., Koistinen, J., Tulppo, M. P., Peng, C. K., et al. (1997). Dynamic analysis of heart rate may predict subsequent ventricular tachycardia after myocardial infarction. Am. J. Cardiol. 80, 779-783. doi: 10.1016/S0002-9149(97)00516-X

Mann, J. J., and Stoff, D. M. (1997). A synthesis of current findings regarding neurobiological correlates and treatment of suicidal behavior. Ann. N.Y. Acad. Sci. 836, 352-363. doi: 10.1111/j.1749-6632.1997.tb52370.x 
Medeiros, A., Oliveira, E. M., Gianolla, R., Casarini, D. E., Negrao, C. E., and Brum, P. C. (2004). Swimming training increases cardiac vagal activity and induces cardiac hypertrophy in rats. Braz. J. Med. Biol. Res. 37, 1909-1917. doi: 10.1590/S0100-879X2004001200018

Mendelowitz, D. (1996). Firing properties of identified parasympathetic cardiac neurons in nucleus ambiguus. Am. J. Physiol. 271, H2609-H2614.

Mezzacappa, E. S., Kelsey, R. M., Katkin, E. S., and Sloan, R. P. (2001). Vagal rebound and recovery from psychological stress. Psychosom. Med. 63, 650-657.

Miczek, K. A. (1979). A new test for aggression in rats without aversive stimulation: differential effects of d-amphetamine and cocaine. Psychopharmacology 60, 253-259. doi: 10.1007/BF00426664

Mueller, P. J., and Hasser, E. M. (2006). Putative role of the NTS in alterations in neural control of the circulation following exercise training in rats. Am. J. Physiol. Regul. Integr. Comp. Physiol. 290, R383-R392. doi: 10.1152/ajpregu.00455.2005

Nalivaiko, E. (2006). 5-HT(1A) receptors in stress-induced cardiac changes: a possible link between mental and cardiac disorders. Clin. Exp. Pharmacol. Physiol. 33, 1259-1264. doi: 10.1111/j.1440-1681.2006.04521.x

Nalivaiko, E., and Sgoifo, A. (2009). Central 5-HT receptors in cardiovascular control during stress. Neurosci. Biobehav. Rev. 33, 95-106. doi: 10.1016/j.neubiorev.2008.05.026

Neto, O. B., Abate, D. T., Junior, M. M., Mota, G. R., Orsatti, F. L., Silva, R. C., et al. (2013). Exercise training improves cardiovascular autonomic activity and attenuates renal damage in spontaneously hypertensive rats. J. Sports Sci. Med. $12,52-59$.

Netzer, F., Bernard, J. F., Verberne, A. J., Hamon, M., Camus, F., Benoliel, J. J., et al. (2011). Brain circuits mediating baroreflex bradycardia inhibition in rats: an anatomical and functional link between the cuneiform nucleus and the periaqueductal grey. J. Physiol. 589, 2079-2091. doi: 10.1113/jphysiol. 2010.203737

Ngampramuan, S., Baumert, M., Beig, M. I., Kotchabhakdi, N., and Nalivaiko, E. (2008). Activation of 5-HT(1A) receptors attenuates tachycardia induced by restraint stress in rats. Am. J. Physiol. Regul. Integr. Comp. Physiol. 294, R132-R141. doi: 10.1152/ajpregu.00464.2007

Nolan, R. P., Jong, P., Barry-Bianchi, S. M., Tanaka, T. H., and Floras, J. S. (2008). Effects of drug, biobehavioral and exercise therapies on heart rate variability in coronary artery disease: a systematic review. Eur. J. Cardiovasc. Prev. Rehabil. 15, 386-396. doi: 10.1097/HJR.0b013e32 83030a97

Parsey, R. V., Oquendo, M. A., Ogden, R. T., Olvet, D. M., Simpson, N., Huang, Y. Y., et al. (2006). Altered serotonin 1A binding in major depression: a [carbonylC-11]WAY100635 positron emission tomography study. Biol. Psychiatry 59, 106-113. doi: 10.1016/j.biopsych.2005.06.016

Porges, S. W. (1995a). Cardiac vagal tone: a physiological index of stress. Neurosci. Biobehav. Rev. 19, 225-233. doi: 10.1016/0149-7634(94)00066-A

Porges, S. W. (1995b). Orienting in a defensive world: mammalian modifications of our evolutionary heritage. A Polyvagal Theory. Psychophysiology 32, 301-318. doi: 10.1111/j.1469-8986.1995.tb01213.x

Porges, S. W. (2007). The polyvagal perspective. Biol. Psychol. 74, 116-143. doi: 10.1016/j.biopsycho.2006.06.009

Rennie, K. L., Hemingway, H., Kumari, M., Brunner, E., Malik, M., and Marmot, M. (2003). Effects of moderate and vigorous physical activity on heart rate variability in a British study of civil servants. Am. J. Epidemiol. 158, 135-143. doi: 10.1093/aje/kwg120

Rentero, N., Cividjian, A., Trevaks, D., Pequignot, J. M., Quintin, L., and McAllen, R. M. (2002). Activity patterns of cardiac vagal motoneurons in rat nucleus ambiguus. Am. J. Physiol. Regul. Integr. Comp. Physiol. 283, R1327-R1334. doi: 10.1152/ajpregu.00271.2002

Reyes Del Paso, G. A., Langewitz, W., Mulder, L. J., Van Roon, A., and Duschek, S. (2013). The utility of low frequency heart rate variability as an index of sympathetic cardiac tone: a review with emphasis on a reanalysis of previous studies. Psychophysiology 50, 477-487. doi: 10.1111/psyp.12027

Rosenwinkel, E. T., Bloomfield, D. M., Arwady, M. A., and Goldsmith, R. L. (2001). Exercise and autonomic function in health and cardiovascular disease. Cardiol. Clin. 19, 369-387. doi: 10.1016/S0733-8651(05)70223-X

Rossi, B. R., Mazer, D., Silveira, L. C., Jacinto, C. P., Di Sacco, T. H., Blanco, J. H., et al. (2009). Physical exercise attenuates the cardiac autonomic deficit induced by nitric oxide synthesis blockade. Arq. Bras. Cardiol. 92, 31-38. doi: 10.1590/S0066-782X2009000100006
Rozanski, A., Blumenthal, J. A., and Kaplan, J. (1999). Impact of psychological factors on the pathogenesis of cardiovascular disease and implications for therapy. Circulation 99, 2192-2217. doi: 10.1161/01.CIR.99.16.2192

Sabbah, H. N., Ilsar, I., Zaretsky, A., Rastogi, S., Wang, M., and Gupta, R. C. (2011). Vagus nerve stimulation in experimental heart failure. Heart Fail. Rev. 16, 171-178. doi: 10.1007/s10741-010-9209-Z

Sant'Ana, J. E., Pereira, M. G., Dias Da Silva, V. J., Dambros, C., Costa-Neto, C. M., and Souza, H. C. (2011). Effect of the duration of daily aerobic physical training on cardiac autonomic adaptations. Auton. Neurosci. 159, 32-37. doi: 10.1016/j.autneu.2010.07.006

Schwartz, P. J., Vanoli, E., Stramba-Badiale, M., De Ferrari, G. M., Billman, G. E., and Foreman, R. D. (1988). Autonomic mechanisms and sudden death. New insights from analysis of baroreceptor reflexes in conscious dogs with and without a myocardial infarction. Circulation 78, 969-979. doi: 10.1161/01.CIR.78.4.969

Sevoz-Couche, C., Brouillard, C., Camus, F., Laude, D., De Boer, S. F., Becker, C., et al. (2013). Involvement of the dorsomedial hypothalamus and the nucleus tractus solitarii in chronic cardiovascular changes associated with anxiety in rats. J. Physiol. 591, 1871-1887. doi: 10.1113/jphysiol.2012.247791

Sgoifo, A., Carnevali, L., and Grippo, A. J. (2014). The socially stressed heart. Insights from studies in rodents. Neurosci. Biobehav. Rev. 39C, 51-60. doi: 10.1016/j.neubiorev.2013.12.005

Sgoifo, A., De Boer, S. F., Buwalda, B., Korte-Bouws, G., Tuma, J., Bohus, B., et al. (1998). Vulnerability to arrhythmias during social stress in rats with different sympathovagal balance. Am. J. Physiol. 275, H460-H466.

Sgoifo, A., Stilli, D., Medici, D., Gallo, P., Aimi, B., and Musso, E. (1996). Electrode positioning for reliable telemetry ECG recordings during social stress in unrestrained rats. Physiol. Behav. 60, 1397-1401. doi: 10.1016/S00319384(96)00228-4

Sloan, R. P., Shapiro, P. A., Bigger, J. T. Jr., Bagiella, E., Steinman, R. C., and Gorman, J. M. (1994). Cardiac autonomic control and hostility in healthy subjects. Am. J. Cardiol. 74, 298-300. doi: 10.1016/0002-9149(94)90382-4

Smeets, T., Giesbrecht, T., Raymaekers, L., Shaw, J., and Merckelbach, H. (2010) Autobiographical integration of trauma memories and repressive coping predict post-traumatic stress symptoms in undergraduate students. Clin. Psychol. Psychother. 17, 211-218. doi: 10.1002/cpp.644

Smith, M. L., Hudson, D. L., Graitzer, H. M., and Raven, P. B. (1989). Exercise training bradycardia: the role of autonomic balance. Med. Sci. Sports Exerc. 21, 40-44. doi: 10.1249/00005768-198902000-00008

Soares-Miranda, L., Sandercock, G., Valente, H., Vale, S., Santos, R., and Mota, J. (2009). Vigorous physical activity and vagal modulation in young adults. Eur. J. Cardiovasc. Prev. Rehabil. 16, 705-711. doi: 10.1097/HJR.0b013e328 $3316 \mathrm{~cd} 1$

Souza, G. G., Magalhaes, L. N., Cruz, T. A., Mendonca-De-Souza, A. C., Duarte, A. F., Fischer, N. L., et al. (2013). Resting vagal control and resilience as predictors of cardiovascular allostasis in peacekeepers. Stress 16, 377-383. doi: $10.3109 / 10253890.2013 .767326$

Souza, H. C., De Araujo, J. E., Martins-Pinge, M. C., Cozza, I. C., and MartinsDias, D. P. (2009). Nitric oxide synthesis blockade reduced the baroreflex sensitivity in trained rats. Auton. Neurosci. 150, 38-44. doi: 10.1016/j.autneu. 2009.04.007

Stein, P. K., Bosner, M. S., Kleiger, R. E., and Conger, B. M. (1994). Heart rate variability: a measure of cardiac autonomic tone. Am. Heart J. 127, 1376-1381. doi: 10.1016/0002-8703(94)90059-0

Task Force of the European Society of Cardiology and the North American Society of Pacing and Electrophysiology. (1996). Heart rate variability: standards of measurement, physiological interpretation and clinical use. Circ. Res. 93, 1043-1065. doi: 10.1161/01.CIR. 93.5.1043

Trombini, M., Hulshof, H. J., Graiani, G., Carnevali, L., Meerlo, P., Quaini, F., et al. (2012). Early maternal separation has mild effects on cardiac autonomic balance and heart structure in adult male rats. Stress 15, 457-470. doi: 10.3109/10253890.2011.639414

Tsai, M. W., Chie, W. C., Kuo, T. B., Chen, M. F., Liu, J. P., Chen, T. T., et al. (2006). Effects of exercise training on heart rate variability after coronary angioplasty. Phys. Ther. 86, 626-635.

Volders, P. G. (2010). Novel insights into the role of the sympathetic nervous system in cardiac arrhythmogenesis. Heart Rhythm 7, 1900-1906. doi: 10.1016/j.hrthm.2010.06.003 
Wood, S. K., McFadden, K. V., Grigoriadis, D., Bhatnagar, S., and Valentino, R. J. (2012). Depressive and cardiovascular disease comorbidity in a rat model of social stress: a putative role for corticotropin-releasing factor. Psychopharmacology 222, 325-336. doi: 10.1007/s00213-012-2648-6

Conflict of Interest Statement: The authors declare that the research was conducted in the absence of any commercial or financial relationships that could be construed as a potential conflict of interest.

Received: 03 February 2014; paper pending published: 01 March 2014; accepted: 10 March 2014; published online: 24 March 2014.
Citation: Carnevali L and Sgoifo A (2014) Vagal modulation of resting heart rate in rats: the role of stress, psychosocial factors, and physical exercise. Front. Physiol. 5:118. doi: 10.3389/fphys.2014.00118

This article was submitted to Clinical and Translational Physiology, a section of the journal Frontiers in Physiology.

Copyright (c) 2014 Carnevali and Sgoifo. This is an open-access article distributed under the terms of the Creative Commons Attribution License (CC BY). The use, distribution or reproduction in other forums is permitted, provided the original author(s) or licensor are credited and that the original publication in this journal is cited, in accordance with accepted academic practice. No use, distribution or reproduction is permitted which does not comply with these terms. 